\title{
PENGEMBANGAN TTCT-V (TORRANCE TEST OF CREATIVE THINKING VERBAL) BERBASIS LINGKUNGAN UNTUK TINGKAT SMA
}

\author{
Lailah Fauziah $^{1)}$, Fitri Rizkiyah ${ }^{2)}$, Mieke Miarsyah ${ }^{3)}$, Rizhal Hendi Ristanto ${ }^{4)}$ \\ ${ }^{1), 2,3), 4)}$ Program Studi Pendidikan Biologi, Universitas Negeri Jakarta \\ emaill):lailah.fauziah26@gmail.com \\ email $^{2}$ : fitri.rizqiyah.pipit@gmail.com \\ email $^{3}$ : mmiarsyah@unj.ac.id \\ email $^{4)}$ :rizalhendi@unj.ac.id
}

\begin{abstract}
ABSTRAK: Kemampuan berpikir kreatif perlu dimiliki oleh para siswa dalam mempelajari berbagai persoalan terkait lingkungan. Tujuan dari penelitian ini yaitu untuk mendesain instrumen tes yang dapat mengukur kemampuan berpikir kreatif siswa SMA pada pokok bahasan pencemaran lingkungan. Instrumen dikembangkan berdasarkan indikator dan bentuk tes verbal yang dicetuskan oleh Torrance. Metode penelitian yang digunakan adalah metode penelitian dan pengembangan (research and development) dengan model 4D yang dicetuskan oleh Tiagarajan, Semmel, dan Semmel (1974). Instrumen yang dibuat divalidasi oleh 4 validator ahli (1 dosen biologi S1 dan 3 guru biologi SMA yang berpengalaman dalam dunia pendidikan selama $>5$ tahun). Berdasarkan uji validitas yang dilakukan didapatkan hasil dengan kategori sangat valid atau layak digunakan. Instrumen ini dapat membantu pendidik dalam menentukan strategi pembelajaran apa yang cocok diterapkan guna mendukung perkembangan kemampuan berpikir kreatif siswa.
\end{abstract}

Kata Kunci: Berpikir Kreatif, Research and Development, Tes verbal Torrance

ABSTRACT: Students need to have creative thinking skills in studying various problems related to the environment. The purpose of this research is to design a test instrument that can measure the creative thinking skills of high school students on the subject of environmental pollution. The instrument was developed based on indicators and the form of a verbal test proposed by Torrance. The research method used is the method of research and development (research and development) with the 4D model proposed by Tiagarajan, Semmel, and Semmel (1974). The instrument made was validated by 4 expert validators (1 undergraduate biology lecturer and 3 high school biology teachers with experience in education for $>5$ years). Based on the validity test carried out, the results were categorized as very valid or suitable for use. This instrument can help educators determine what learning strategies are suitable to be applied to support the development of students' creative thinking abilities.

Keywords: Creative Thinking, Research and Development, Torrance Verbal Test

\section{PENDAHULUAN}

Lingkungan merupakan salah satu komponen kehidupan yang keadaannya sangat bergantung pada aktivitas manusia, sehingga perubahan selalu terjadi seiring dengan perkembangan zaman. Dara impact matter (ditugaskan oleh Climate Vulnerable Forum) menuliskan laporan bahwa 100 
juta jiwa terancam mati, mulai dari saat ini sampai dengan akhir dekade berikutnya. Hal ini terjadi oleh akibat dampak negatif dari akumulasi karbon yang cukup tinggi di atmosfer.

Permasalah terkait dampak negatif dari perubahan yang terjadi pada lingkungan memerlukan pendekatan kreatif untuk memecahkannya (Reid, 1994). Pendekatan kreatif mencakup dimensi kognitif yaitu berpikir kreatif yang merupakan kemampuan seseorang dalam menghasilkan berbagai macam jawaban atau ide pemecahan ketika dihadapi oleh sebuah masalah melalui proses berpikir (Isiyono, et al, 2018). Aspek berpikir kreatif diantaranya yaitu kelancaran, fleksibilatas, dan mengarah ke ide-ide baru atau wawasan baru dalam sebuah masalah yang ada (Reid, 1994).

Mempelajari aspek-aspek kehidupan yang membahas terkait permasalahan lingkungan serta mengembangkan kemampuan berpikir kreatif yang dapat digunakan untuk memecahkannya, ditekanan oleh Menteri Pendidikan Indonesia untuk diterapkan dalam sistem pendidikannya.

Penekanan seseorang untuk memiliki kreatifitas dalam dimensi kognitif (berpikir kreatif) dipaparkan juga oleh Trilling (2009). Trilling mengatakan bahwa berpikir kreatif adalah kemampuan yang dibutuhkan di abad 21 ini, abad dimana terjadinya perkembangan yang sangat pesat dalam ilmu pengetahuan, teknologi dan informasi. Sehingga atmosfer kehidupanpun lebih kompetitif.

Kemapuan berpikir kreatif seseorang dapat diidentifikasi melalui sebuah tes kreatifitas. Alat tes Torrance yang dapat mengukur berpikir kreatif salah satunya yaitu bentuk tes verbal. Bentuk verbal terdiri dari beberapa sub-tes diantaranya yaitu : 1) Ask and guess; 2) Guessing causes and guessing consequences; 3) Unusual use activity; 4) improvement activity; 5) Just suppose activity (The Alberta Teachers' Association, 2014).

TTCT-V (Torrance Test of Creative Thinking Verbal) menilai pada tiga aspek berpikir kreatif di antaranya yaitu : 1) Fluency, dimana anak dapat memberikan banyak ide dengan katakata; 2) Flexibility, yaitu anak dapat memberikan berbagai ide, bergeser dari satu pendekatan ke pendekatan lain, atau menggunakan berbagai strategi; 3) Originality, kemampuan anak untuk menghasilkan ide yang tidak biasa (Torrance, 2018).

Adapun penelitian-penelitian sebelumnya terkait pemikiran kreatif yang mengacu pada jenis tes yang dikemukakan ahli lain seperti Guilford (Roosyanti, 2017). Beberapa peneliti mengembangkan instrumen yang dapat menilai/mengukur siswa di setiap aspek kognitif dalam kreatifitas (berpikir kreatif) pada pembelajaran materi fisika dan matematika (Isiyono, 2018).

Identifikasi yang dilakukan oleh para pendidik pada setiap aspek berpikir kreatif yang dimiliki siswa dapat membantu menentukan strategi pengajaran apa yang sesuai untuk mengembangkan kemampuan berpikir kreatif siswanya agar menjadi lebih baik.

Berdasarkan permasalahan tersebut, penelitian bertujuan untuk mengembangkan sebuah instrumen TTCT-V yang dapat digunakan oleh para guru biologi di Indonesia dalam mengukur peserta didik dalam setiap aspek berpikir kreatif dalam 
mempelajari materi pencemaran lingkungan yang diajarkan pada jenjang SMA kelas X.

\section{METODE PENELITIAN}

Metode yang digunakan pada kegiatan penelitian ini yaiitu research and development dengan mengikuti prosedur yang dicetuskan oleh Tiagarajan, Semmel, dan Semmel (1974) yaitu 4D. Tahapan model 4D tersebut diantaranya yaitu (Bagan. 1): 1) Define; 2) Design; 3) Develope; 4) Desseminate.

Bagan 1. Tahap model 4D Tiagarajan, Semmel dan Semmel (1974)

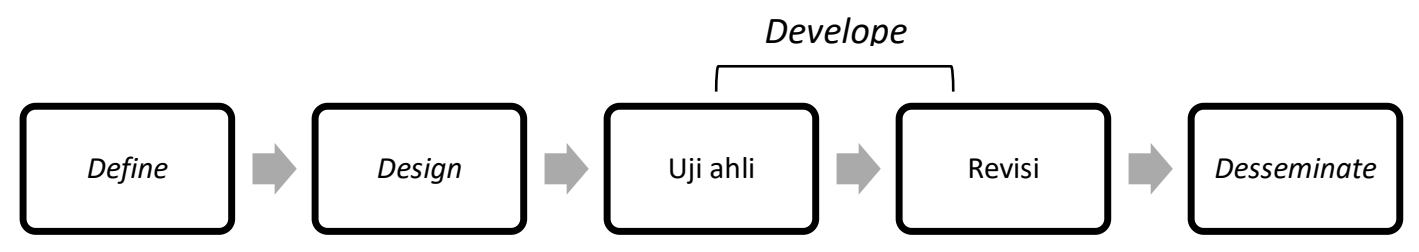

Pada tahap pertama yaitu menentukan tujuan dari alat yang akan dikembangkan, melalui analisis materi dan kompetensi yang akan diukur. Tujuan dikembangkannya alat ini adalah untuk membuat sebuah instrumen tes yang dapat digunakan oleh para pendidik untuk mengukur (mengidentifikasi/menilai) kemampuan berpikir kreatif yang dimilki oleh siswa dalam memahami materi pencemaran lingkungan.

Pada tahap kedua yaitu mendesain intrumen tes tersebut berdasarkan teori

\begin{tabular}{|c|c|c|}
\hline $\begin{array}{l}\text { Nama } \\
\text { Subtes }\end{array}$ & $\begin{array}{c}\text { Indikator Kemampuan } \\
\text { Berpikir Kreatif }\end{array}$ & Soal \\
\hline $\begin{array}{l}\text { Ask and } \\
\text { guess }\end{array}$ & $\begin{array}{l}\text { 1. Fluency } \\
\text { Membuat pertanyaan- } \\
\text { pertanyaan yang dapat } \\
\text { ditafsirkan, bermakna, } \\
\text { dan relevan dengan } \\
\text { gambar yang ditampilkan } \\
\text { 2. Flexibility } \\
\text { Membuat pertanyaan- }\end{array}$ & $\begin{array}{l}\text { Gambar di bawah ini merupakan keadaan } \\
\text { yang sering dijumpai jika kamu tinggal di } \\
\text { perkotaan besar. Buatlah pertanyaan } \\
\text { sebanyak mungkin dengan membanyangkan } \\
\text { kamu berada pada foto ini! }\end{array}$ \\
\hline
\end{tabular}

Bio-Lectura: Jurnal Pendidikan Biologi, Vol 8, No 1, April 2021

yang dikemukakan oleh ahli. Dalam hal ini peneliti menyusun kisi-kisi tes yang mengacu pada aspek-aspek berpikir kreatif (fluency, flexibility, dan originality) dan bentuk tes verbal yang dikemukakan oleh Torrance. Bentuk tes berupa uraian terbuka yang jawabannya tidak dibatasi dan mengacu pada kompetensi dasar 3.10 kurikulum 2013 sistem pendidikan Indonesia. Berikut kisi-kisi instrumen tes yang dibuat: 


\begin{tabular}{|c|c|c|}
\hline & $\begin{array}{l}\text { pertanyaan yang relevan } \\
\text { namun berbeda kategori } \\
\text { 3. Originality } \\
\text { Memberikan pertanyaan } \\
\text { berbeda dari siswa } \\
\text { lainnya }\end{array}$ & $\begin{array}{l}\text { (sumber: cnnindonesia.com) } \\
\text { (sumes }\end{array}$ \\
\hline \multirow[b]{2}{*}{$\begin{array}{l}\text { Guessin } \\
\text { g causes } \\
\text { and } \\
\text { guessin } \\
g \\
\text { consequ } \\
\text { ences }\end{array}$} & $\begin{array}{l}\text { 1. Fluency } \\
\text { Memperkirakan akibat } \\
\text { suatu peristiwa pada } \\
\text { gambar secara relevan } \\
\text { 2. Flexibility } \\
\text { Memperkirakan akibat } \\
\text { suatu peristiwa pada } \\
\text { gambar secara relevan } \\
\text { namun berbeda kategori } \\
\text { 3. Originality } \\
\text { Memberikan tanggapan } \\
\text { original yang berbeda dari } \\
\text { siswa lainnya }\end{array}$ & $\begin{array}{l}\text { (sumber: tribunnews.com) } \\
\text { Gambar di atas merupakan keadaan jalan } \\
\text { raya sekitar sekolahmu yang dipenuhi } \\
\text { dengan kendaraan penghasil asap, suara } \\
\text { bising knalpot dan klakson. Tuliskan } \\
\text { kemungkinan peristiwa yang dapat terjadi } \\
\text { apabila keadaan seperti pada gambar di atas } \\
\text { terjadi secara terus menerus! }\end{array}$ \\
\hline & $\begin{array}{l}\text { 1. Fluency } \\
\text { Memperkirakan penyebab } \\
\text { terjadinya suatu peristiwa } \\
\text { pada gambar secara } \\
\text { relevan } \\
\text { 2. Flexibility } \\
\text { Memperkirakan penyebab } \\
\text { terjadinya suatu peristiwa } \\
\text { pada gambar secara } \\
\text { relevan namun berbeda } \\
\text { kategori } \\
\text { 3. Originality } \\
\text { Memberikan tanggapan } \\
\text { original yang berbeda dari } \\
\text { siswa lainnya }\end{array}$ & $\begin{array}{l}\text { Kampung halamanmu berada di sekitar } \\
\text { sungai besar di dekat pertambangan di mana } \\
\text { banyak penduduk yang membuat tambak } \\
\text { ikan. Suatu ketika kamu mengunjungi } \\
\text { kampungmu, kamu menemui keadaan } \\
\text { seperti gambar di bawah ini : } \\
\text { (sumber: acehbisnis.com) } \\
\text { Tuliskan kemungkinan penyebab terjadinya } \\
\text { peristiwa pada gambar! Jelaskan secara } \\
\text { detil! }\end{array}$ \\
\hline $\begin{array}{l}\text { Unusual } \\
\text { use } \\
\text { activity }\end{array}$ & 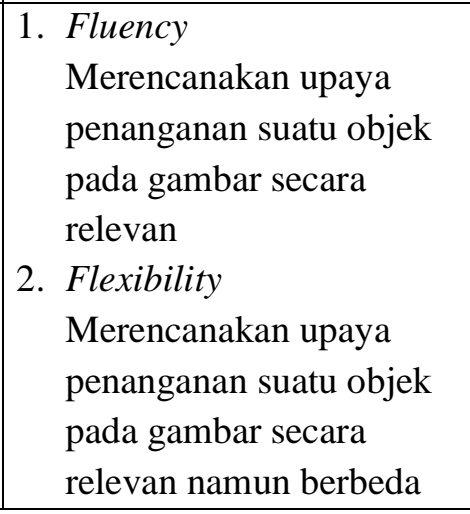 & $\begin{array}{l}\text { Di sekitar sekolahmu terdapat pedagang es } \\
\text { kelapa yang sangat kamu dan temanmu } \\
\text { sukai. Setiap hari pedagang ini membuka } \\
\text { banyak kelapa. Namun, kian hari limbah } \\
\text { kelapa itu menumpuk dan dibiarkan berada } \\
\text { di tepi seperti gambar di bawah ini. } \\
\text { Pedagang tersebut tidak sempat } \\
\text { membersihkannya dan tidak ada truk } \\
\text { sampah yang bisa masuk ke dalam jalan } \\
\text { sekolahmu yang sempit. }\end{array}$ \\
\hline
\end{tabular}




\begin{tabular}{|c|c|c|}
\hline & $\begin{array}{l}\text { kategori } \\
\text { 3. Originality } \\
\text { Merencanakan upaya } \\
\text { penanganan suatu objek } \\
\text { pada gambar secara } \\
\text { original yang berbeda dari } \\
\text { siswa lainnya }\end{array}$ & $\begin{array}{l}\text { (sumber: dokumen pribadi) } \\
\text { Sebagai seorang siswa yang sering melewati } \\
\text { jalan ini dan marasa tergannggu karena bau } \\
\text { dan lalat yang kerap muncul juga } \\
\text { pemandangan yang tidak bagus. Apa yang } \\
\text { dapat kamu dan temanmu buat dari sampah } \\
\text { ini? }\end{array}$ \\
\hline & & 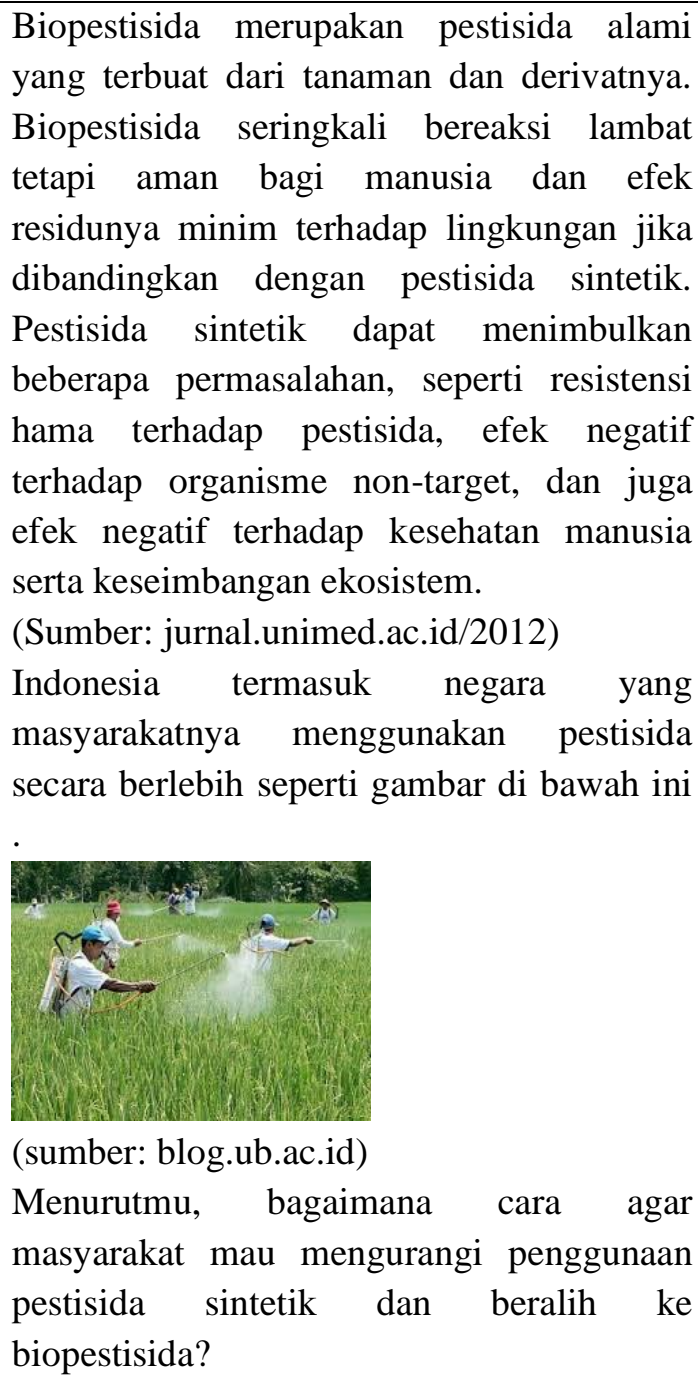 \\
\hline $\begin{array}{l}\text { Product } \\
\text { improve } \\
\text { ment } \\
\text { activity }\end{array}$ & $\begin{array}{l}\text { 1. Fluency } \\
\text { Memberikan solusi yang } \\
\text { mungkin untuk mengubah } \\
\text { suatu permasalahan } \\
\text { secara relevan. } \\
\text { 2. Flexibility }\end{array}$ & $\begin{array}{l}\text { Setiap hari pada jam istirahat sampah } \\
\text { menumpuk dan berceceran di kelas serta } \\
\text { mengotori lingkungan sekolah seperti } \\
\text { gambar di bawah ini. Sebagai siswa apa } \\
\text { yang bisa kamu lakukan untuk mengatasi } \\
\text { hal ini? }\end{array}$ \\
\hline
\end{tabular}




\begin{tabular}{|c|c|c|}
\hline & $\begin{array}{l}\text { Memberikan solusi yang } \\
\text { mungkin untuk mengubah } \\
\text { suatu permasalahan } \\
\text { secara relevan namun } \\
\text { berbeda kategori } \\
\text { 3. Originality } \\
\text { Memberikan solusi yang } \\
\text { mungkin untuk mengubah } \\
\text { suatu permasalahan } \\
\text { secara relevan dan } \\
\text { berbeda dari siswa } \\
\text { lainnya }\end{array}$ & $\begin{array}{l}\text { (sumber: biologismp37.blogspot.com) } \\
\text { sungai. Dahulu sungai tersebut sangat bersih } \\
\text { sehingga setiap orang sangat bergantung } \\
\text { pada sungai ini untuk melakukan aktivitas } \\
\text { sehari-hari. Hingga sekarang sungai tersebut } \\
\text { masih digunakan walau tak sebersih dulu } \\
\text { seperti gambar di bawah ini. Menurutmu, } \\
\text { usaha apa saja yang dapat dilakukan untuk } \\
\text { mengurangi tindakan-tindakan seperti pada } \\
\text { gambar di bawah ini? } \\
\text { a is a } \\
\text { (sumber: radarcirebon.com) }\end{array}$ \\
\hline $\begin{array}{l}\text { Just } \\
\text { suppose } \\
\text { activity }\end{array}$ & $\begin{array}{l}\text { 1. Fluency } \\
\text { Memperkirakan } \\
\text { kemungkinan hasil dan } \\
\text { konsekuensi dari } \\
\text { peristiwa penting yang } \\
\text { dapat ditafsirkan, } \\
\text { bermakna, dan relevan } \\
\text { dengan gambar yang } \\
\text { ditampilkan } \\
\text { 2. Flexibility } \\
\text { Memperkirakan } \\
\text { kemungkinan hasil dan } \\
\text { konsekuensi dari } \\
\text { peristiwa penting yang } \\
\text { relevan namun berbeda } \\
\text { kategori } \\
\text { Originality } \\
\text { Memperkirakan } \\
\text { kemungkinan hasil dan } \\
\text { konsekuensi dari } \\
\text { peristiwa penting secara } \\
\text { original yang berbeda dari }\end{array}$ & $\begin{array}{l}\text { Pariwisata di Indonesia merupakan salah } \\
\text { satu penghasil pendapatan negara yang } \\
\text { tinggi. Oleh sebab itu pemeritah terus } \\
\text { mengembangkan daerah-daerah Indonesia } \\
\text { yang berpotensi sebagai tujuan pariwisata. } \\
\text { Salah satu destinasi pariwisata yang sangat } \\
\text { digemari adalah pantai sebagaimana gambar } \\
\text { di bawah ini! } \\
\text { (sumber: Liputan6.com) } \\
\text { Menurutmu bagaimanakah dampak } \\
\text { pariwisata ini terhadap lingkungan pada } \\
\text { gambar tersebut di masa depan? }\end{array}$ \\
\hline
\end{tabular}




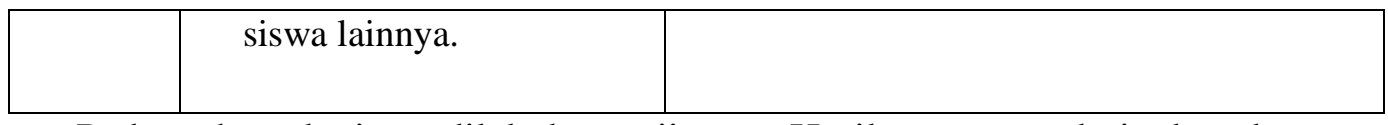

Pada tahap ketiga, dilakukan uji validasi pada beberapa ahli untuk mengetahui kualitas instrumen tes. Uji validasi dilakukan dengan 5 validator ahli dan menggunakan kriteria validasi menurut Ratumanan dan Laurens (2006). Berikut tabel kriteria validasi ahli :

Tabel 2 Kriteria validasi ahli

\section{Interval Category Criteria}

$\begin{array}{ll}1,75>x>1,00 & \text { Tidak Valid } \\ 2,50 \geq x \geq 1,75 & \text { Cukup Valid } \\ 3,25 \geq x \geq 2,50 & \text { Valid } \\ 4,00 \geq x>3,25 & \text { Sangat Valid }\end{array}$

Sumber : Ratumanan \& Laurens (2006)

Item pada intrumen diperbaiki berdasarkan masukan dari para ahli agar versi akhir intrumen yang dikembangkan memiliki kualitas yang baik dan efektif dalam mengukur.

Pada tahap keempat yaitu dessemnate (produksi/penyebaran), kegiatan terhambat oleh adanya pendemi Covid 19 sehingga proses penyebaran instrumen di lapangan tidak dapat dilakukan.

\section{HASIL DAN PEMBAHASAN}

Pengembangan instrumen TTCT-V (Torrance Test of Creative Thinking Verbal) yang telah dilakukan menghasilkan 8 butir soal. Validasi yang dilakukan adalah validasi ahli dengan melibatkan empat orang ahli. Sedangkan untuk uji instrumen kepada siswa tidak dapat dilakukan karena keterbatasan dan keadaan lapangan yang tidak memungkinkan.
Hasil rata-rata dari skor keempat validator ahli pada Tabel 3 adalah sebesar 3.58 yang termasuk ke dalam kategori sangat valid. Namun, terdapat beberapa catatan yang diberikan beberapa validator ahli yang perlu diperhatikan. Catatan pertama dari Ahli satu menyatakan bahwa instrumen sangat baik akan tetapi lebih baik untuk dieksplorasi lagi agar lebih dapat memicu siswa dalam berpikir kreatif. Sedangkan ahli dua memberikan catatan berkaitan jumlah soal yang terlalu banyak. Jumlah awal soal sebanyak 20 butir, diberikan kepada validator ahli untuk dinilai. Jumlah tersebut dikhawatirkan akan membebani siswa, terlebih soal yang diberikan dalam bentuk uraian.

Tahap revisi kemudian dilakukan dengan melakukan perbaikan dan pengurangan butir soal berdasarkan pertimbangan hasil penilaian dan catatan validator ahli. Instrumen dikurangi sebanyak 12 soal dari total 20 soal. Setiap soal yang dihilangkan merupakan soal dengan indikator yang dianggap telah terwakili pada soal sebelumnya, baik indikator pembelajaran maupun indikator subtes berpikir kreatif Torrance. Soal yang dikurangi juga dianggap terlalu umum dan kurang dapat memicu siswa dalam memerlihatkan kemampuan berpikir kreatif siswa. 
Tabel 3. Hasil Penilaian Instrumen Oleh Ahli

\begin{tabular}{lccccc}
\hline Penilaian Butir Instrumen & $\begin{array}{c}\text { Ahli } \\
\mathbf{1}\end{array}$ & $\begin{array}{c}\text { Ahli } \\
\mathbf{2}\end{array}$ & $\begin{array}{c}\text { Ahli } \\
\mathbf{3}\end{array}$ & $\begin{array}{c}\text { Ahli } \\
\text { Aspek Sajian }\end{array}$ & Rata-rata \\
\hline $\begin{array}{l}\text { Butir Instrumen dapat } \\
\text { mengukur kemampuan } \\
\text { berpikir kreatif }\end{array}$ & 4 & 4 & 4 & 3 & 3.75 \\
\hline $\begin{array}{l}\text { Penyajian butir soal ditulis } \\
\text { secara sistematis }\end{array}$ & 4 & 3 & 4 & 4 & 3.75 \\
\hline $\begin{array}{l}\text { Instrumen mewakili setiap } \\
\text { indikator pembelajaran }\end{array}$ & 4 & 4 & 4 & 5 & 4 \\
\hline $\begin{array}{l}\text { Instrumen dibuat } \\
\text { menyesuaikan kondisi siswa }\end{array}$ & 4 & 2 & 4 & 3 & 3.25 \\
$\begin{array}{l}\text { SMA } \\
\text { Instrumen disajikan secara }\end{array}$ & 4 & 4 & 3 & 4 & 3.75 \\
jelas dan mudah dipahami & & & & & \\
\hline $\begin{array}{l}\text { Aspek kreatif thinking } \\
\text { Torrance terwakili pada butir } \\
\text { intrumen }\end{array}$ & 4 & 4 & 4 & 4 & 4 \\
\hline
\end{tabular}

\section{Aspek Kebahasaan}

\begin{tabular}{lccccc}
\hline $\begin{array}{l}\text { Penggunaan bahasa yang } \\
\text { komunikatif }\end{array}$ & 4 & 3 & 4 & 4 & 3.75 \\
\hline $\begin{array}{l}\text { Penggunaan bahasa yang } \\
\text { jelas dapat dipahami }\end{array}$ & 3 & 3 & 3 & 4 & 3.75 \\
\hline $\begin{array}{l}\text { Penggunaan kaidah EYD } \\
\text { (Ejaan Yang }\end{array}$ & 2 & 3 & 4 & 3 & 3 \\
$\begin{array}{l}\text { Disempurnakan) pada setiap } \\
\text { butir soal }\end{array}$ & 3 & 3 & 4 & 3 & 3.25 \\
\hline $\begin{array}{l}\text { menyesuakan konteks pada } \\
\text { setiap butir soal }\end{array}$ & 3.6 & 3.3 & 3.8 & 3.6 & 3.58 \\
\hline Rata-rata & $\begin{array}{c}\text { sangat } \\
\text { valid }\end{array}$ & $\begin{array}{c}\text { sangat } \\
\text { valid }\end{array}$ & $\begin{array}{c}\text { sangat } \\
\text { valid }\end{array}$ & $\begin{array}{c}\text { sangat } \\
\text { valid }\end{array}$ & $\begin{array}{c}\text { sangat } \\
\text { valid }\end{array}$ \\
\hline Kategogri & & & & &
\end{tabular}

Bentuk soal yang dikembangkan agar siswa dapat dengan mudah dalam TTCT-V berupa uraian yang memberikan jawaban-jawaban yang disesuaikan dengan tes verbal. Tujuan tidak terbatas berdasarkan apa yang diberikannya soal dalam bentuk uraian mereka pikirkan. Sehingga, penilaian 
untuk melihat kemampuan berpikir kreatif siswa juga akan mudah dilakukan. Kemampuan berpikir kreatif merupakan salah satu kemampuan berpikir divergen yaitu pemikiran yang melibatkan beberapa jawaban untuk masalah yang sering dengan bebas didefinisikan (Chermahini, et al., 2012). Sedangkan, soal pilihan ganda cenderung dipakai untuk mencari solusi tunggal dan sangat terbatas untuk suatu masalah sehingga kurang cocok untuk diterapkan dalam mengukur kemampuan berpikir kreatif. Penilaian setiap jawaban akan disesuaikan berdasarkan komponen penilaian aspek berpikir kreatif tes verbal yaitu fluency, flexibility, dan originality (Kim, 2017).

Meskipun tes ini merupakan tes verbal, setiap soal diberikan stimulus gambar yang menjadi ciri khas tes berpikir kreatif Torrance dengan penambahan stimulus berupa narasi permasalahan. Stimulus berfungsi untuk menyediakan kondisi interaksi yang dapat mengembangkan dan membantu siswa dalam mengeksplorasi (Justica, et al., 2015). Stimulus berupa gambar dapat mengarahkan siswa untuk fokus pada contoh peristiwa sehingga dapat memberikan produk atau solusi kreatif dari berbagai elemen yang ada pada gambar (Chrysikou, et al., 2017).

Setiap butir soal disesuaikan dengan permasalahan yang terjadi dan dapat ditemui di kehidupan sehari-hari. Hal ini bertujuan agar dapat menumbuhkan rasa kesadaran siswa terhadap lingkungan. Faktor kognitif terkait dengan tingkat kesadaran terhadap lingkungan, pengetahuan tentang konsep lingkungan, dan kemampuan pribadi untuk mengambil tindakan (Ozkan-Pir \& Karaduman, 2017; Niankara \& Zoungrana, 2018). Sehingga dengan soal-soal yang memiliki keeratan dengan kehidupan sehari-hari dapat memacu kemampuan berpikir kreatif siswa dalam memecahkan permasalahan lingkungan.

Beberapa butir soal juga meminta siswa untuk meramalkan dampak yang mungkin akan terjadi dari suatu peristiwa yang ditampilkan. memungkinkan siswa untuk berimajinasi terhadap sesuatu yang belum terjadi dan memungkinkan munculnya originality siswa. Kemampuan berimajinasi secara original adalah keterampilan yang digunakan untuk menghasilkan ide-ide baru atau tidak biasa (Kim, 2017).

Keseluruhan butir soal pada TTCT$\mathrm{V}$ memungkinkan guru untuk menilai tingkat berpikir kreatif siswa secara efektif. Tidak seperti asesmen berpikir kreatif lainnya, di mana setiap butir soal dikhususkan untuk mengukur satu aspek indikator berpikir kreatif seperti fluency, flexibility, atau hanya originality saja. Instrumen soal yang dikembangkan berdasarkan pendekatan Torrance ini dapat memfasilitasi seluruh aspek berpikir kreatif di dalam satu soal. Penekan penilaiannya tidak pada kunci jawaban, akan tetapi pada kuantitas, ketepatgunaan dan keragaman jawaban yang dapat diukur (Tirtawati, et al., 2014), serta menyesuaikan pada kategori subtes yang ada. Sehingga penggunaan sedikit soal di dalam proses penilaian sangat memungkinkan untuk dilakukan.

Hasil dari asesmen berpikir kreatif ini akan menunjukkan bagaimana kualitas siswa dalam berpikir dan bertindak. Semakin tinggi skor siswa dalam tes berpikir kreatif ini, semakin tinggi pula tingkatan aspek berpikir kreatif yang dimiliki. Siswa yang menempati skor teratas juga menempati 
peringkat teratas dalam pekerjaan kreatif (Shen \& Lai, 2014).

Tes kemampuan berpikir kreatif ini pula membantu siswa untuk berpikir kritis dan dapat mencari solusi bagi suatu permasalahan, oleh sebab itu penggunaannya dalam mengevaluasi materi pencemaran sangat dapat diterapkan. Pada umumnya kegiatan penilaian di sekolah khususnya pada mata pelajaran Biologi hanya menitik beratkan pada pertanyaan seputar teoritik dan hafalan semata. Sehingga, dengan adanya asesmen menggunakan tes kemampuan berpikir kreatif ini siswa dapat mengkonstruksi sendiri pemahamannya melalui pengalaman dan pengamatan yang dimilikinya.

\section{KESIMPULAN}

Hasil penelitian yang telah diperoleh dapat menyimpulkan bahwa TTCT-V (Torrance Test of Creative Thinking Verbal) berbasis Lingkungan untuk Tingkat SMA yang dikembangkan valid dan dapat digunakan dalam evaluasi (penilaian) siswa untuk mengukur kemampuan berpikir kreatif. Selain dapat melihat kemampuan berpikir kreatif, tes ini juga dapat memperlihatkan kemampuan kognitif dan pemecahan masalah siswa.

Tes yang dikembangkan dalam penelitian ini adalah tes verbal berdasarkan teori Torrance, disarankan untuk penelitian lanjutan dapat menggunakan tes figural berdasarkan teori Torrance.

\section{DAFTAR PUSTAKA}

Chermahini, S. A., Hickendorff, M., \& Hommel, B. 2012. Development and validity of a Dutch version of the Remote Associates Task: An item-response theory approach.
Thinking Skills and Creativity, 7(3), 177-186.

Chrysikou, E. G., Motyka, K., Nigro, C., Yang, S. I., \& Thompson-Schill, S. L. 2016. Functional fixedness in creative thinking tasks depends on stimulus modality. Psychology of Aesthetics, Creativity, and the Arts, 10(4), 425.

Isiyono, E, Dwandaru, D. B., \& Rahayu, F. 2018. Pengembangan Tes Creative Thinking Skills Fisika SMA (PhysCreTHOTS)

Berdasarkan Teori Tes Modern. Cakrawala Pendidikan, (2), :190200.

Justica, A. A., Azrai, E. P., \& Suryanda, A. 2015. The Effect of The-Teaching-With-Analogies Model Application on Learning Science to Creative Thinking Skill of Student on Junior High School. Biosfer: Jurnal Pendidikan Biologi, 8(1), 51-56.

Kemendikbud. 2016. Peraturan Menteri Pendidikan dan Kebudayaan Republik Indonesia Nomor 21 Tahun 2016 tentang Standar Isi Pendidikan Dasar Dan Menengah.http://sdm.data.kemdikb ud.go.id/snp/uploud/dokumen/2017 0224114501.pdf

Kim, K. H. 2010. Measurements, Causes, and Effects of Creativity. Psychology of Aesthetics, Creativity, and the Arts, 4, 131135.

Kim, K. H. 2011. The Creativity Crisis: The Decrease in Creative Thinking Scores on the Torrance Tests of Creative Thinking. Creativity Research Journal, 23(4), 285-295. 
Kim, K. H. 2017. The Torrance Tests of Creative Thinking-Figural or Verbal: Which One Should We Use?. Creativity. TheoriesResearch-Applications, 4(2), 302321.

Menteri Pendidikan dan Kebudayaan Republik Indonesia. 2016. Salinan Lampiran Peraturan Menteri Pendidikan dan Kebudayaan Nomor 20 Tahun 2016 Tentang Standar Kompetensi Lulusan Pendidikan Dasar dan Menengah. Diakses pada 23 Juni 2020 di https://bsnpindonesia.org/wpcontent/uploads/2 009/04/Permendikbud_Tahun2016_ Nomor020_Lampiran.pdf.

Niankara, I., \& Zoungrana, D. T. 2018. Interest in the biosphere and students environmental awareness and optimism: A global perspective. Global Ecology and Conservation, 16.

Ratumanan, T. ., \& Laurens, T. 2006. Evaluasi Hasil Belajar yang Relevan dengan Kurikulum Berbasis Kompetensi. Surabaya: Unesa University Press.

Reid, R. K. 1994. Creative Thinking Exercise. The American Biology Teacher, 56(4), 226-228.

Roosyanti, A. 2017. Pengembangan Perangkat Pembelajaran Berorientasi Pendekatan Guided Discovery untuk Melatihkan Keterampilan Berpikir Kritis dan Kreatif. Jurnal Pena Sains, 4(1): 60-73.
Shen, T., \& Lai, J. C. 2014. Exploring the Relationship Between Creative Test of ATTA and the Thinking of Creative Works. Procedia-Social and Behavioral Sciences, 112, 557566.

The Alberta Teachers' Association. 2014. 3 Examples- Torrance Teast of Creative Thinking (TTCT). Diakses pada 23 Juni 2020 di https://innovators-guide.ch/wpcontent/uploads/2012/12/torrancecreativity-test.pdf.

Thompson, T. L., \& Mintzes, J. J. 2002. Cognitive Structure and the Affective Domain: on Knowing and Feeling in Biology. International Journal of Science Education, 24(6), 645-660.

Tirtawati, N. L. R., Adnyana, P. B., \& Widiyanti, N. L. P. M. 2014. Pengaruh Pembelajaran Kuantum (Quantum Learning) dan Peta Pikiran (Mind Mapping) Terhadap Keterampilan Berpikir Kreatif Dan Hasil Belajar Biologi Siswa SMA. Jurnal Pendidikan dan Pembelajaran IPA Indonesia, 4(2).

Torrance, E. P. 2018. Torrance Test of Creative Thinking. Bensenville: Scholastic Testing Service.

Trilling, B., Ernie \& Charles, F. C. 2009. 21 st Century Skills: Learning for Life In Our Times. San Francisco: Jossey-Bass A Wiley Imprint. 